\title{
New Cr-Ni-Base Alloy for High-Temperature Applications Designed on the Basis of First Principles Calculations
}

\author{
V. I. Razumovskiy (D, ${ }^{1}$ D. Scheiber, ${ }^{1}$ I. M. Razumovskii, ${ }^{2}$ V. N. Butrim, ${ }^{2}$ \\ A. S. Trushnikova, ${ }^{2}$ S. B. Varlamova, ${ }^{2}$ and A. G. Beresnev ${ }^{2}$ \\ ${ }^{1}$ Materials Center Leoben Forschung GmbH, Roseggerstraße 12, 8700 Leoben, Austria \\ ${ }^{2}$ Joint-Stock Company "Kompozit", Pionerskaya St. 4, Korolev, Moscow Region 141070, Russia \\ Correspondence should be addressed to V. I. Razumovskiy; vsevolod.razumovskiy@mcl.at
}

Received 4 January 2018; Accepted 1 February 2018; Published 9 July 2018

Academic Editor: Yuxiang Ni

Copyright (C) 2018 V. I. Razumovskiy et al. This is an open access article distributed under the Creative Commons Attribution License, which permits unrestricted use, distribution, and reproduction in any medium, provided the original work is properly cited.

\begin{abstract}
We use ab initio calculations to analyze the influence of $4 \mathrm{~d}$ and $5 \mathrm{~d}$ transition metal alloying elements on cohesive properties of the bulk and a representative grain boundary in $\mathrm{Cr}$ within the framework of the Rice-Thomson-Wang approach. The results obtained for $\mathrm{Cr}$ are combined with the analogous results for $\mathrm{Ni}$ to select $\mathrm{Ta}$ and $\mathrm{Nb}$ as promising alloying additions to dual-phase $(\alpha / \gamma)$ $\mathrm{Cr}-\mathrm{Ni}$-base high-temperature alloys. Ta and $\mathrm{Nb}$ are added to the alloying system of an existing alloy I (Cr-Ni-W-V-Ti) in an attempt to design a chemical composition of a new alloy II (Cr-Ni-W-V-Ti) + (Ta-Nb). Investigation of the microstructure of the Ta-bearing $\mathrm{Cr}$-Ni-alloy reveals a Ta enrichment of large $\gamma$-areas near GBs in $\alpha$-matrix that we consider as potency to increase the cohesive strength of GBs and the cohesive energy of the bulk in $\gamma$-phase. Mechanical testing of alloys I and II demonstrates that the alloy II has improved tensile strength and creep resistance at high temperatures.
\end{abstract}

\section{Introduction}

Traditional materials for production of critical components of gas-turbine engines, where significant resistance to loading at high temperatures is required, are Ni-base superalloys $[1,2]$. One of the most important performance characteristics of Ni-base superalloys is their creep resistance. In the polycrystalline critical parts, for example, turbine disks $[3,4]$, one of the weakest elements of microstructure is grain boundaries (GBs). GBs are normally characterized by enhanced diffusivity [5], which leads to increased creep at high temperatures. One can include into the alloying system elements that segregate to GBs and increase their work of separation $W_{\text {sep }}$ in order to strengthen GBs and improve their creep resistance. The $W_{\text {sep }}$ is a fundamental thermodynamic quantity that controls the mechanical strength of an interface and allows one to study the problem of GB embrittlement from first principles using the Rice-Thomson-Wang model $[6,7]$. In accordance with the low alloying additions concept $[8,9]$, the "useful" alloying addictions have to increase simultaneously the cohesive strength of GBs and the cohesive energy of the bulk. By such an approach, $\mathrm{Ta}, \mathrm{Nb}, \mathrm{Zr}$, and $\mathrm{Hf}$ have been predicted to be beneficial alloying addictions to $\mathrm{Ni}$ base alloys and used to design a new polycrystalline Ni-base superalloy for powder metallurgy applications [10].

The main weakness of Ni-base superalloys for high-temperature applications is insufficient corrosion resistance. One of the most effective approaches to improve this is alloying with $\mathrm{Cr}$. Cr-Ni-base high-temperature alloys represent their own type of superalloys [11], which is of great practical importance, for instance, for manufacturing combustion chambers of thermocatalytic engines intended for correction of the orbit and orientation of a spacecraft [12]. Such alloys typically have the following chemical composition: $\mathrm{Cr}-(31-35) \mathrm{Ni}-$ (1-3)W-(0.1-0.4)V-(0.05-0.3)Ti, wt.\% (alloy I, [13]), and they consist of two major metallic phases: $\alpha$ (solid solution based on Cr with bcc lattice) and $\gamma$ (solid solution based on $\mathrm{Ni}$ with fcc lattice). A distinguishing feature of their microstructure is formation of large $\gamma$-phase areas near GBs in $\alpha$-matrix. The deformation behavior of the whole $\alpha+\gamma$ microstructure in this type of alloys is controlled by $\gamma$-phase due to its high degree of ductility [14]. 
At first sight, it seems attractive to add the same elements that are beneficial for Ni-base alloys, which are $\mathrm{Zr}, \mathrm{Hf}, \mathrm{Nb}$, and $\mathrm{Ta}$, also into $\mathrm{Cr}$-Ni-base alloys to obtain stronger GBs in the $\gamma$-phase. However, the influence of the aforementioned elements on the cohesive properties of $\alpha$-matrix remains unknown and data dealing with $\mathrm{Zr}, \mathrm{Hf}, \mathrm{Nb}$, and Ta influence on mechanical properties of Cr-base alloys are controversial [17]. That is why it is important to investigate an embrittling potency of $\mathrm{Zr}, \mathrm{Hf}, \mathrm{Nb}$, and $\mathrm{Ta}$ in $\mathrm{Cr}$-base solid solutions as well.

In this paper, we investigate first the effect of a number of transition metals including $\mathrm{Zr}, \mathrm{Hf}, \mathrm{Nb}$, and $\mathrm{Ta}$ on the cohesive properties of the bulk $\alpha$-phase and a representative GB in $\mathrm{Cr}$ alloys using ab initio calculations. Second, we determine the embrittling potency of $4 \mathrm{~d}$ and $5 \mathrm{~d}$ transition metals in $\mathrm{Cr}$ alloys in the framework of the low alloying additions concept $[8,9]$. Finally, we introduce the elements acceptable for both $\alpha$ and $\gamma$ phases into a typical alloy to fabricate a new $\mathrm{Cr}-\mathrm{Ni}$ base alloy and investigate its microstructure and mechanical properties.

\section{Computational Details}

2.1. Electronic Structure Calculations. Electronic structure calculations have been performed using the projector augmented wave method [18] as implemented in Vienna ab initio simulation package (VASP) $[19,20]$ with generalized gradient approximation (GGA) [21]. Since the primary interest of the present study is in the cohesive properties of $\mathrm{Cr}$-Ni-base alloys at elevated temperatures, all calculations have been performed at a relevant high-temperature bcc lattice constant of $2.92 \AA[22]$. As the magnetic moment of the high-temperature paramagnetic phase of chromium has been shown to be zero within the framework of the disordered local moment model (see for instance [23]), we have performed only non-spinpolarized calculations. The convergence accuracy of the total energy has been chosen as $10^{-5} \mathrm{eV}$ and $9 \times 10^{-3} \mathrm{eV} / \mathrm{A}$ for the forces. The ionic relaxations have been included in the all types of calculations.

2.2. Semiempirical Calculations. The semiempirical simulations made use of the second nearest neighbor modified embedded atom method (2NN-MEAM) potentials [24] within the LAMMPS environment $[25,26]$. These potentials were developed specifically for bcc metals, for which the contribution of the second nearest neighbors is not to be neglected. The simulation cells were set up with the equilibrium lattice constant of the potential; that is, $a 0=2.88 \AA$. For the relaxations, the Hessian-free truncated Newton algorithm was selected, and the chosen convergence criterion for the relaxation was relative energy changes between iterations of less than $10^{-11}$ and a 2-norm of the global force vector of less than $10^{-13} \mathrm{eV} / \AA$.

2.3. Grain Boundary and Free Surface Modeling. A special coincident site lattice (CSL) model GB $\Sigma 5$ (210) [100] and a free surface (FS) (210) have been used in all DFT calculations as a representative GB and the corresponding surface created after the GB cleavage. The GB has been modeled by a

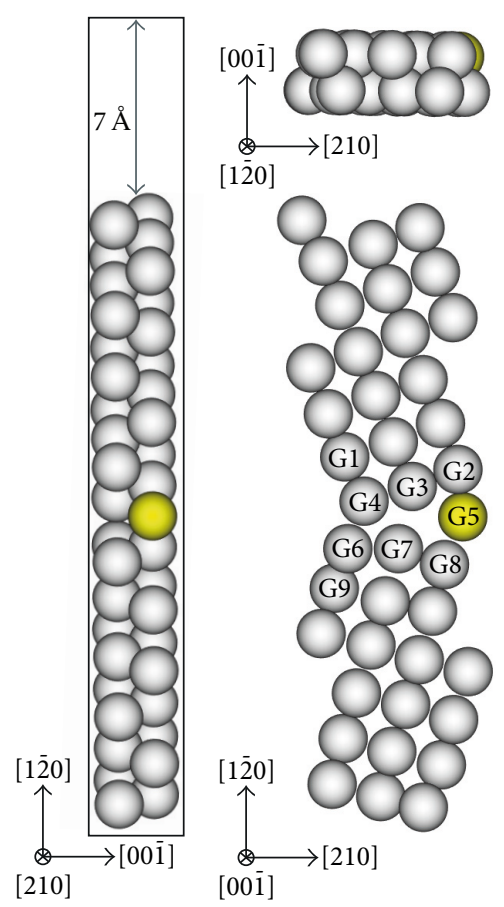

Figure 1: The supercell used in the model calculations of the $\Sigma 5$ (210) [100] GB between bcc Cr grains. The yellow sphere indicates the substitutional site used for impurity segregation.

supercell containing 40 atomic layers of $\mathrm{Cr}$ (one atom per layer) separated by $7 \AA$ of vacuum as shown in Figure 1 . The same supercell, but without GB, has been used for the free surface (FS) calculations. Only substitutional sites have been considered for the GB and surface segregation of $4 \mathrm{~d}$ and $5 \mathrm{~d}$ impurities. The $8 \times 4 \times 2$ Monkhorst-Pack [27] $k$-point mesh has been used for GB and FS calculations, whereas the $6 \times 6$ $\times 6$ mesh has been employed in pure bulk calculations with a 54-atom bcc supercell. The structure of $\Sigma 5$ (210) [100] GB has been additionally relaxed by shifting two grains in the slab with respect to each other. The found minimum energy structure (shown in Figure 1) has been used in all GB slab calculations.

For the semiempirical GB simulations, the size of the simulation cells was increased due to the low computational cost. Therefore, the size of the grains normal to the GB was set to at least $30 \AA$ for each grain separated, which were separated by $7 \AA$ of vacuum. A large set of different GB structures was built using the atomic simulation environment (ASE) python package [28], and, analogous to the DFT simulations, the minimum energy structure was identified for each of these GBs by shifting the grains with respect to each other.

\section{Methodology}

3.1. The Concept of Low Alloying Additions. In accordance with the Rice-Thomson-Wang approach $[6,7]$ the mechanical strength of a solid/solid interface (GB) is determined by the work of separation $W_{\text {sep}}$, which is easily accessible from first principles ( $a b$ initio) calculations based on density 
functional theory (DFT) [29]. Here, we use $W_{\text {sep }}$ within the concept of low alloying additions described in detail in $[8,9]$ to characterize the influence of $4 \mathrm{~d}$ and $5 \mathrm{~d}$ transition metals on the cohesive strength of selected alloys. As discussed in $[8,9]$, the alloying elements will be selected using the following three criteria:

(i) a positive partial cohesive energy [30]

$$
\chi_{i}=\frac{\partial E_{i}^{\mathrm{coh}}}{\partial c_{i}}
$$

where $E_{i}^{\mathrm{coh}}$ is the cohesive energy of an alloy and $c_{i}$ is the concentration of an $i$ th component. $\chi_{i}$ characterizes an influence of impurities on the cohesive energy of the bulk of alloy, and an increase in bulk cohesion is indicated by positive value of $\chi_{i}$.

(ii) a negative change in work of separation per impurity atom, that is, the strengthening energy $\eta$ :

$$
\eta=\frac{W_{\mathrm{sep}}^{0}-W^{\mathrm{sep}}}{\Gamma}=E_{\mathrm{gb}}^{\mathrm{seg}}-E_{\mathrm{fs}}^{\mathrm{seg}},
$$

where $W_{\text {sep }}^{0}$ is the work of separation of a GB in pure $\mathrm{Cr}, W^{\text {sep }}$ is the work of separation of this GB with an impurity, $\Gamma$ is the impurity excess at the $\mathrm{GB}, E_{\mathrm{gb}}^{\mathrm{seg}}$ is the impurity segregation energy to the $\mathrm{GB}$, and $E_{\mathrm{fs}}^{\mathrm{seg}}$ is the impurity segregation energy to the FS. $\eta$ characterizes the influence of impurities on the GB strength with negative values corresponding to an increase in GB strength.

(iii) a negative GB segregation energy defined for a substitutional impurity as

$$
\begin{aligned}
E_{\text {seg }}^{\mathrm{gb}}= & E_{\text {slab }}^{\mathrm{gb}}[N-1 ; 1]-E_{\text {slab }}^{\mathrm{gb}}[N ; 0]+\Delta_{\text {bulk }}^{\mathrm{Ni} \longrightarrow X}+\varepsilon_{\text {slab }}^{0} \\
& -\varepsilon_{\text {bulk }}^{0},
\end{aligned}
$$

where $E_{\text {slab }}^{\mathrm{gb}}[n ; m]$ represents the total energy of the GB supercell containing $n$ host atoms and $m$ impurity atoms. The term $\Delta_{\text {bulk }}^{\mathrm{Ni} \rightarrow X}$ is the energy difference between two bulk supercells before and after one of the host atoms is replaced by an impurity atom. In order to achieve a better cancellation of numerical errors originating from the $k$-point sampling and the finite size of the plane-wave basis set, we must distinguish between the energy of the $\mathrm{Cr}$ atom obtained from the cubic 54-atom bcc supercell $\varepsilon_{\text {bulk }}^{0}$ bulk and the same energy calculated in the slab supercell (by completely filling it up with layers of $\mathrm{Cr}$, i.e., the socalled "space filling slab"), $\varepsilon_{\text {slab }}^{0}$. Both $\varepsilon_{\text {bulk }}^{0}$ and $\varepsilon_{\text {slab }}^{0}$ are the total energies of the respective cells divided by the number of atoms. We apply a similar formula for the case of the free surface (FS) substitutional segregation used in (3):

$$
\begin{aligned}
E_{\text {seg }}^{\mathrm{fs}}= & \frac{\left(E_{\text {slab }}^{\mathrm{fs}}[N-2 ; 2]-E_{\text {slab }}^{\mathrm{gb}}[N ; 0]\right)}{2}+\Delta_{\text {bulk }}^{\mathrm{Ni} \rightarrow X} \\
& +\varepsilon_{\text {slab }}^{0}-\varepsilon_{\text {bulk }}^{0},
\end{aligned}
$$

where $E_{\text {slab }}^{\mathrm{fs}}[n ; m]$ represents the total energy of the FS supercell containing $n$ host and $m$ impurity atoms.

All parameters entering the formulae above can be determined using ab initio calculations based on DFT. This procedure has already been applied to $\mathrm{Ni}[8,9]$, which is why the focus of ab initio calculations in this paper lays primarily on the investigation of the influence of the series of $4 \mathrm{~d}$ and $5 \mathrm{~d}$ transition metals on the cohesive strength of $\mathrm{Cr}$. The data from our previous study of $\mathrm{Ni}[8,9]$ will be used along with the current data on $\mathrm{Cr}$ for the composition design of a new Cr-Ni alloy.

\subsection{Choice of Representative Grain Boundary and Segregation}

Site. Parameters $\eta$ and $E_{\text {seg }}^{\mathrm{gb}}$ for each impurity atom are calculated using a representative GB and a representative segregation site. To select a suitable GB structure, we have performed a systematic scan of a number of GB geometries in $\mathrm{Cr}$ using 2NN-MEAM calculations. The GB energies of these GBs are plotted in Figure 3 and demonstrate that the GB energy is highly anisotropic. While two $\Sigma 3$ GBs exhibit GB energies below $0.5 \mathrm{~J} / \mathrm{m}^{2}$, most GBs display higher GB energies within the range $1-1.5 \mathrm{~J} / \mathrm{m}^{2}$. As can be seen in Figure 3, the $\Sigma 5$ (210) [100] GB already used in [31] represents a reasonable compromise due to its minimal structure size ( 40 atoms) and due to the fact that its GB energy falls in the midrange of special GBs formation energies in Cr. There is a large offset between DFT and 2NN-MEAM data in the case of the $\Sigma 5$ (210) [100] GB, but a similar deviation of 2NN-MEAM data from DFT has been observed in the case of Fe calculations, which can be traced back to a fitting of the 2NN-MEAM potentials to experimental surface energies that are in general below the values found with DFT [16]. However, as it has been shown also in [16], MEAM and DFT provide qualitatively the same results for Fe. Therefore, 2NN-MEAM results may be used for a relative energy analysis.

The site preference within the selected $\Sigma 5$ (210) [100] GB has been checked by calculating the segregation energies of a Ta-impurity at G1-G9 GB sites in the vicinity of the GB (see Figure 1). The results show that G5 and G7 sites have almost identical values (within $0.01 \mathrm{eV}$ ) of $E_{\mathrm{seg}}^{\mathrm{gb}}$ with the absolute minimum at G5 site. In what follows, we will use this GB site (GB5) for $\eta$ and $E_{\text {seg }}^{\text {gb }}$ calculations. By doing so, we assume that since all $4 \mathrm{~d}$ and $5 \mathrm{~d}$ impurities are larger in size than $\mathrm{Cr}$ [32], they will exhibit the same site preference as one of the largest impurity atoms $(\mathrm{Ta})$. Such trends have already been observed in other systems, for example, for $4 \mathrm{~d}$ and $5 \mathrm{~d}$ impurities in Mo and $\mathrm{W}$ [33] or selected solutes in Fe [34].

\section{Theoretical Results}

4.1. Pure Cr. In Table 1, we compare our results for the $\Sigma 5$ (210) [100] GB and the corresponding (210) free surface (FS) energies of pure Cr. A direct comparison to the DFT data from Ossowski et al. [31] shows good qualitative agreement between two sets of calculations. Ossowski et al. have investigated the same GB and FS geometries. We relate the differences in absolute values for both GB and 
TABLE 1: The (210) free surface $\gamma_{0}^{\mathrm{FS}}$ and the $\Sigma 5(210)$ [100] GB $\gamma_{0}^{\mathrm{GB}}$ energies of pure Cr in $\mathrm{J} / \mathrm{m}^{2}$. The results are compared to DFT data from $[31,35,36]$ and experimental data from $[37,38]$.

\begin{tabular}{lcccccc}
\hline & \multirow{2}{*}{ This work } & \multicolumn{2}{c}{ Theory } & \multicolumn{2}{c}{ Experiment } \\
& & Ossowski et al. [31] & Ossowski and Kiejna [36] & Vitos et al. [35] & De Boer [37] & Tyson and Miller [38] \\
\hline$\gamma_{0}^{\mathrm{FS}}$ & 2.90 & 3.31 & 3.40 & $3.10-4.12$ & 2.30 & 2.35 \\
$\gamma_{0}^{\mathrm{GB}}$ & 1.83 & 2.52 & - & - & - & - \\
\hline
\end{tabular}

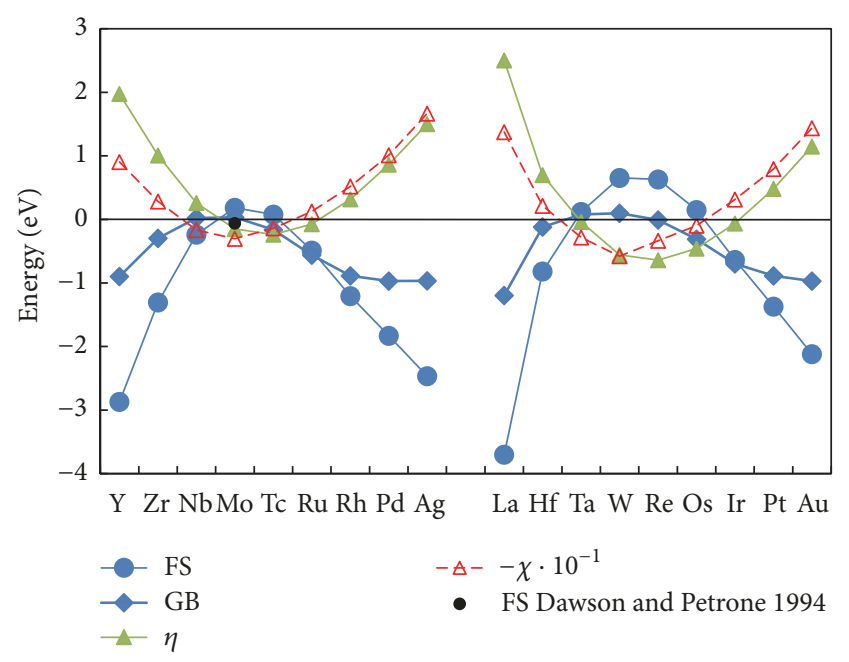

FIgURE 2: Transition element segregation energies to $\Sigma 5$ (210) [100] GB (filled diamonds) and to (210) FS (filled circles), the GB strengthening energy $\eta$ (filled triangles) and partial cohesive energies $\chi$ (empty triangles) in bcc Cr. An experimental data point related to Mo free surface (FS) segregation in a Cr-rich Cr-Mo alloy from [15] is shown with a black circle.

FS energies to the differences in the exchange correlation functional, the assumed magnetic states, and the relaxation procedures employed in the calculations. Here, we have performed an additional minimum energy search in the GB plane by shifting two grains with respect to each other and scanning the energy landscape for the minimum energy configuration. The results for the FS energy are also compared to the DFT data from Vitos et al. [35] obtained for a set of different surface planes (excluding (210)) without local atomic relaxations, DFT data from Ossowski and Kiejna for the (210) FS [36], and available experimental data [37, 38] (not surface facet specific). Taking into account the scatter in FS energies expected for different FS facets from [35], the FS energy predicted in our calculations can be considered to be in good agreement with the available experimental data (representing an averaged FS energy) as well.

4.2. Impurity in Bulk. First, we analyze a possible cohesive strengthening effect of the impurity atoms in the bulk of $\mathrm{Cr}$ using the partial cohesive energy $\chi_{i}$. The calculated values of $\chi_{i}$ are shown in Figure 2. The elements from the middle of the transition elements series have the largest strengthening effect. This trend is in agreement with an analogous trend for

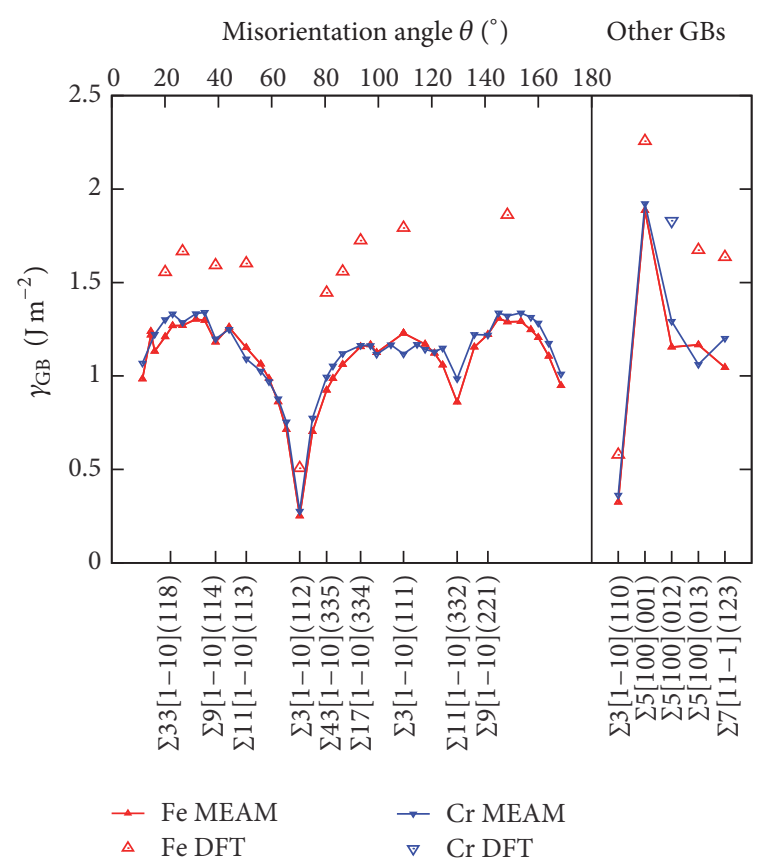

FIGURE 3: GB energies for different GBs with a [110] rotation axis (left) and selected other GBs (right) from 2NN-MEAM simulations (connected lines) and DFT calculations (unconnected symbols). The downward pointing triangles denote results for $\mathrm{Cr}$ (this study), while the upward pointing triangles stand for Fe results from [16].

$4 \mathrm{~d}$ and $5 \mathrm{~d}$ impurities in Ni-matrix. The elements improving the bulk cohesive strength in $\mathrm{Cr}$ are $\mathrm{Nb}, \mathrm{Mo}$, Tc from the $4 \mathrm{~d}$ and $\mathrm{Ta}, \mathrm{W}, \mathrm{Re}, \mathrm{Os}$, from the $5 \mathrm{~d}$ series.

4.3. Impurity Segregation. Results for the segregation energies from first principles calculations of $4 \mathrm{~d}$ and $5 \mathrm{~d}$ transition elements to the FS (210) and to the $\Sigma 5$ (210) [100] GB are presented in Figure 2. The trend for the segregation energies with respect to the d-band filling displays some wave-like features, somewhat different from what has been observed for $\mathrm{Ni}[8,9]$; however, it resembles closely the trend found for d-band filling in Mo and W (site 1 in Figures 2 and 3 in [33]), which suggests that this trend is related to the d-band filling of the host element. The only experimental data point available for comparison is related to Mo segregation in a Crrich Cr-Mo alloy [15], where the segregation energy of Mo to the FS was found by means of the Auger spectroscopy to be virtually zero $(-0.06 \mathrm{eV} / \mathrm{at})$. This result is similar to the result of our calculations for Mo (210) surface where we also see 


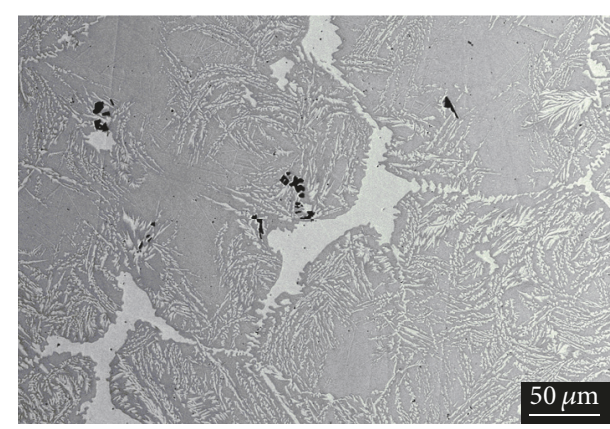

(a)

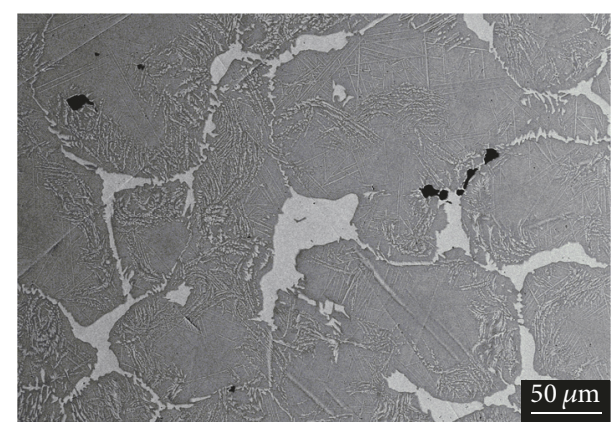

(b)

Figure 4: A typical microstructure of the Cr-Ni-base alloys I (a) and II (b) (SEM, the etched surface of the sample). Note of the large areas (light) of $\gamma$-phase near GBs in $\alpha$-matrix (dark).

an essentially zero segregation energy with a slight tendency towards antisegregation (see Figure 2).

The strengthening energy $\eta$ as the difference between segregation to the GB and to the FS is also presented in Figure 2. It follows a trend similar to that of the partial cohesive energy $\chi_{i}$, yet shifted somewhat to right (about one element). According to these results, the elements leading to an increased $\mathrm{GB}$ cohesion if present at the GB are $\mathrm{Mo}, \mathrm{Tc}, \mathrm{Ru}$, Ta, W, Re, Os, and Ir.

Figure 2 shows a correlation between the influence of the alloying elements on the bulk and GB cohesion in $\mathrm{Cr}$ : the elements from the middle of the series have the most pronounced cohesive strengthening effect on the cohesion while the elements from the beginning and the end of the series have the most pronounced embrittling effect. Such behavior is similar to the result obtained in [8,9] for $\mathrm{Ni}$ and seems to be a generic feature for alloying with transition elements in dilute limit in general [39].

4.4. Choice of Low Alloying Additions. We use the three main parameters of the low alloying additions concept $\chi_{i}, \eta$, and $E_{\mathrm{seg}}^{\mathrm{gb}}$ $[8,9]$ presented in Figure 2 to identify the cohesion strengthening elements in Cr. Elements with the most remarkable strengthening effect on both GB and bulk are located in the middle of each element series. If we exclude precious and life hazardous elements from our consideration, we identify $\mathrm{Re}, \mathrm{W}, \mathrm{Mo}$, and Ta as the elements with a positive effect on both bulk and GB cohesion. Let us also remark that $\mathrm{Nb}$ (a beneficial addition to Ni-base alloys) only slightly decreases GB strength in Cr but still strengthens the bulk phase. In the $\mathrm{Ni}$ alloys, the most cohesion enhancing elements were identified as $\mathrm{Zr}, \mathrm{Hf}, \mathrm{Nb}$, and $\mathrm{Ta}$ [8, 9]. Consequently, our choice fell on $\mathrm{Ta}$ and $\mathrm{Nb}$, which are the only additions with a $\mathrm{GB}$ and bulk strengthening effect in $\gamma$-phase $(\mathrm{Ni})$, practically neutral for GB in $\alpha$-phase (Cr), and with some strengthening effect in the bulk of $\alpha$-phase. So far as Ta and $\mathrm{Nb}$ have been absent from the alloying system of the typical Cr-Ni-base alloy (Cr, Ni, W, Ti, and V, alloy I), here, we propose to include them into the chemical composition of the Cr-Ni-base alloy as cohesion strengthening elements to design a new test alloy with improved mechanical properties (alloy II).

\section{Experimental Procedure and Results}

5.1. Materials and Methods. The ingots $(\sim 60 \mathrm{~kg})$ of a test alloy II and alloy I have been melted in a vacuum-induction furnace ISV-0.16; electric slag has been remelted and annealed at $900^{\circ} \mathrm{C}$ for 16 hours. The obtained alloys have had the following chemical compositions (wt.\%): alloy I (Cr-32.7Ni$1.92 \mathrm{~W}-0.3 \mathrm{Ti}-0.3 \mathrm{~V})$; alloy II (Cr-32.2Ni-2.06W-0.08Ti-0.29V) $+(0.15 \mathrm{Ta}, 0.16 \mathrm{Nb})[40]$. For mechanical testing, the ingots of the alloys have been hot extruded from the rods $\varnothing 100 \mathrm{~mm}$ to the bars $\varnothing 28 \mathrm{~mm}$ (standard technology for production of the industrial alloy I). The X-ray diffraction (XRD) analysis (Siemens $\mathrm{D} 500 \mathrm{X}$-ray with $\mathrm{Cu}-\mathrm{K} \alpha$ radiation) and scanning electron microscopy (SEM, microscope JEOL JSM 6610LV) have been used to investigate the microstructure of the alloys. We have used the Instron 3382 machine for tensile testing of the samples at 20,900 , and $1080^{\circ} \mathrm{C}$.

5.2. Microstructure of the Test Alloy II. The XRD data demonstrate that alloys I and II consist of the two main phases: $\alpha$ (bcc) and $\gamma$ (fcc). Figure 4 shows a typical microstructure of the Cr-Ni-base alloys I and II after melting, electric slag remelting, and annealing. One can observe a formation of the relatively large light areas $(\gamma)$ that decorate GBs in $\alpha$-matrix and make GBs visible in the microstructure.

A not etched sample of the (Ta, Nb)-bearing alloy, Figure 5 (SEM), was used for investigation of the distribution of the alloying elements in the microstructure. Electron probe microanalysis maps, Figure 5, obtained from micrograph Figure 4 (SEM) demonstrate that the light areas near GBs are enriched with $\mathrm{Ni}$ and dark areas in the core of the grains are enriched with Cr. It is interesting to note that a distribution of $\mathrm{Ta}$ in the microstructure is fully correlated with a distribution of Ni; that means that $\mathrm{Ta}$ is predominantly located in the large $\gamma$-areas near GBs. W, Ti, and V are practically homogeneously distributed in the microstructure.

5.3. Mechanical Testing. The results of tensile mechanical testing at different temperatures of alloys I and II are given in Table 2. One can see that both alloys have practically the same tensile strength $\sigma_{b}$ and elongation $\delta$ at room temperature. However, alloy II demonstrates a remarkable improvement of 

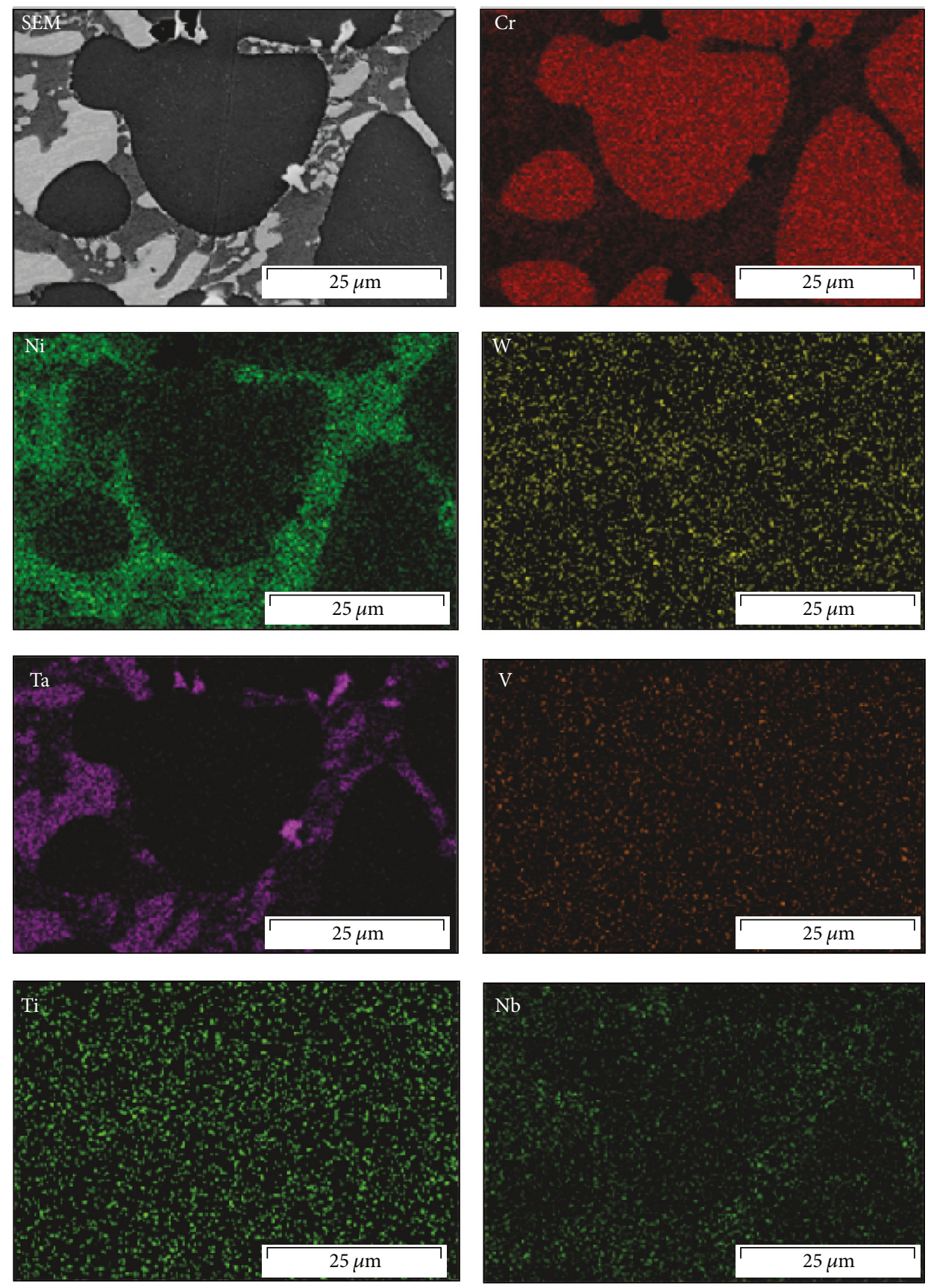

FIGURE 5: Scanning electron micrograph (SEM, not etched sample) and electron probe microanalysis maps of the (Ta, Nb)-bearing alloy after melting, electric slag remelting, and annealing.

TABLE 2: Mechanical properties at different temperatures of alloys I and II.

\begin{tabular}{lcccc}
\hline Alloy & & & & I \\
& & Characteristics & & \\
Temperature, ${ }^{\circ} \mathrm{C}$ & Tensile strength, $\sigma_{b}, \mathrm{MPa}$ & Elongation $\delta, \%$ & Tensile strength, $\sigma_{b}$, MPa & Elongation, $\%$ \\
\hline 20 & 1182 & 20 & 1224 & 17.5 \\
900 & 374 & 24 & 384 & 12.3 \\
1080 & 89 & 136 & 137 & 20.2 \\
\hline
\end{tabular}




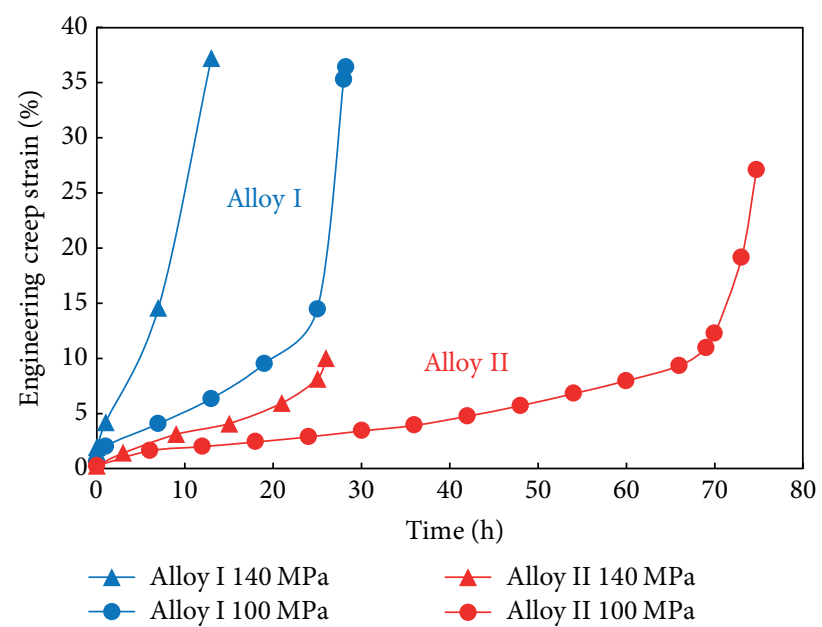

Figure 6: Creep curves at $800^{\circ} \mathrm{C}$ and constant load of $100(\bullet)$ and 140 (A) $\mathrm{MPa}$ for alloys I and II.

the strength at high temperature $1080^{\circ} \mathrm{C}$; namely, the tensile strength $\sigma_{b}$ increases from 89 to $137 \mathrm{MPa}$. In addition, we have been able to suppress unwanted superplastic behavior of the alloy $\mathrm{I}$ at $1080^{\circ} \mathrm{C}$ by reducing the elongation $\delta$ from 136 to $20 \%$.

The results of creep testing of alloys I and II at temperature $800^{\circ} \mathrm{C}$ under loading 100 and $140 \mathrm{MPa}$ are presented in Figure 6, which demonstrates a significant increase in the creep resistance of alloy II due to addition of small amounts of $\mathrm{Ta}$ and $\mathrm{Nb}$ into alloy $\mathrm{I}$.

\section{Conclusions}

We have used DFT calculations to investigate the influence of $4 \mathrm{~d}$ and $5 \mathrm{~d}$ transition metal alloying elements on the bulk and GB cohesive strength in $\mathrm{Cr}$ within the low alloying additions concept based on the ideas of the Rice-Thomson-Wang approach. The results of this investigation have been combined with the analogous results for the $\mathrm{Ni}$ to select $\mathrm{Ta}$ and $\mathrm{Nb}$ as acceptable additions to dual-phase $(\alpha / \gamma) \mathrm{Cr}$-Ni-base alloys. Both elements fit the criteria of the low alloying additions concept and strengthen GB and bulk of both $\gamma$ and $\alpha$ phases best out of all considered $4 \mathrm{~d}$ and $5 \mathrm{~d}$ alloying elements.

These new alloying elements have been used for designing a new test Cr-Ni-base alloy II by means of adding $(0,15 \mathrm{Ta}$, $0,16 \mathrm{Nb})$ to the known $\mathrm{Cr}-\mathrm{Ni}$-base alloy I (Cr-32,2Ni-2,06W$0,08 \mathrm{Ti}-0,29 \mathrm{~V}$ ) (wt.\%). These alloys have been produced by means of melting in a vacuum-induction furnace ISV0.16 , electric slag remelting, and annealing at $900^{\circ} \mathrm{C}$ for 16 hours.

Investigation of the microstructure of Ta-bearing $\mathrm{Cr}-\mathrm{Ni}$ alloy has revealed enrichment of Ta in the large $\gamma$-phase areas near GBs in the $\alpha$-matrix that we consider as a potency to increase simultaneously the cohesive strength of GBs and the cohesive energy of the bulk in $\gamma$-phase. Mechanical testing of both alloys has demonstrated that the test alloy II with Ta and $\mathrm{Nb}$ has had improved tensile strength and creep resistance at high temperatures with respect to the original alloy I.

\section{Data Availability}

The data on DFT segregation and strengthening energies calculations are included in the SEGROcalc database available in https://www.mcl.at/software/segrocalc/.

\section{Conflicts of Interest}

The authors declare that they have no conflicts of interest.

\section{Acknowledgments}

V. I. Razumovskiy would like to thank Professor A. V. Ruban and Dr. A. Kartsev for useful discussions of some of the presented theoretical results. Computer resources at the National Supercomputer Center (NSC) in Linköping were provided by the Swedish National Infrastructure for Computing (SNIC). The financial support under the scope of the COMET program within the K2 Center "Integrated Computational Material, Process and Product Engineering (IC-MPPE)" (Project no. 859480) is gratefully acknowledged. This program is supported by the Austrian Federal Ministries for Transport, Innovation and Technology (BMVIT) and for Digital and Economic Affairs (BMDW), represented by the Austrian Research Funding Association (FFG), and the federal states of Styria, Upper Austria, and Tyrol.

\section{References}

[1] C. T. Sims, N. S. Stoloff, and W. C. Hagel, Superalloys II, Wiley, NY, USA, 1987.

[2] R. C. Reed, The Superalloys: Fundamentals and Applications, Cambridge University Press, Cambridge, UK, 2006.

[3] D. Chang, D. Krueger, and R. Sprague, "Superalloy powder processing, properties, and turbine disk applications," in The Metallurgical Society of AIME, R. H. Bricknell, W. B. Kent, M. Gell, C. S. Kortovich, and J. F. Radavich, Eds., pp. 245-273, Superalloys.

[4] G. S. Garibov and A. V. Vostrikov, "Current trends of PM superalloys discs production technology for gas turbine engines," in Proceedings of the 2005 International Conference Hot Isostatic Press, pp. 86-91, Paris, 2005.

[5] S. Z. Bokshtein, S. S. Ginzburg, S. T. Kishkin, I. M. Razumovskii, and G. B. Stroganov, Autoradiography of Grain and Interphase Boundaries and Structural Stability of Alloys, Moscow, 1987.

[6] J. R. Rice and J.-S. Wang, "Embrittlement of interfaces by solute segregation," Materials Science and Engineering: A Structural Materials: Properties, Microstructure and Processing, vol. 107, no. C, pp. 23-40, 1989.

[7] J. R. Rice and R. Thomson, "Ductile versus brittle behaviour of crystals," Philosophical Magazine, vol. 29, no. 1, pp. 73-97, 1974.

[8] V. I. Razumovskiy, A. Y. Lozovoi, and I. M. Razumovskii, "Firstprinciples-aided design of a new Ni-base superalloy: Influence of transition metal alloying elements on grain boundary and bulk cohesion," Acta Materialia, vol. 82, pp. 369-377, 2015.

[9] V. I. Razumovskiy, A. Y. Lozovoi, and I. M. Razumovskii, "Firstprinciples-aided design of a new Ni-base superalloy: Influence of transition metal alloying elements on grain boundary and bulk cohesion," Acta Materialia, vol. 106, pp. 401-402, 2016.

[10] A. G. Beresnev, A. I. Logacheva, A. V Logachev, A. V Logunov, I. M. Razumovskii, and P. V Taran, "Heat-resistant Granular 
Ni-based Alloy Containing C," Yt and Ni in Specific Weight Percentage, Patent RU2386714-C1, 2010.

[11] J. R. Davis, Nickel, Cobalt, and Their Alloys, ASM International, 2000.

[12] V. N. Butrim, "Technological Aspects of Manufacturing of High-Quality High-Chromium Alloy Semifinished Products for Production of Critical Spacecraft Thruster Components," Light Alloy Technology, vol. 2, pp. 95-104, 2015 (Russian).

[13] G. M. Voronin, S. T. Kishkin, and I. O. Panasyuk, "Refractory alloys for aero- and space scpece applications," in Aviation materials between the 20-21st centuries, G. M. Voronin, S. T. Kishkin, I. O. Panasyuk, V. N. Podyachev, and E. V. Sivakova, Eds., pp. 264-273, Nauka, VIAM, Moscow, 1994.

[14] A. V. Perepelkin, G. F. Sarzhan, S. A. Firstov, and G. G. Kurdyumova, "Investigation of the deformation and rupture mechanisms in two-phase Cr-Ni alloy VKh-4," The Physics of Metals and Metallography, vol. 48, pp. 588-592, 1979.

[15] P. T. Dawson and S. A. Petrone, "Studies on Cr-Mo binary alloys II. Cross-over in surface segregation for chromium-rich alloys," Surface Science, vol. 304, no. 1-2, pp. 119-130, 1994.

[16] D. Scheiber, R. Pippan, P. Puschnig, and L. Romaner, "Ab initio calculations of grain boundaries in bcc metals," Modelling and Simulation in Materials Science and Engineering, vol. 24, no. 3, Article ID 035013, 2016.

[17] E. M. Savitsky and G. S. Burkhanov, Metallurgy of Refractory and Rare Metal Based Alloys, Moscow, 1971.

[18] P. E. Blöchl, "Projector augmented-wave method," Physical Review B: Condensed Matter and Materials Physics, vol. 50, no. 24, pp. 17953-17979, 1994.

[19] G. Kresse and J. Furthmüller, "Efficient iterative schemes for $a b$ initio total-energy calculations using a plane-wave basis set," Physical Review B: Condensed Matter and Materials Physics, vol. 54, no. 16, pp. 11169-11186, 1996.

[20] G. Kresse and J. Furthmüller, "Efficiency of ab-initio total energy calculations for metals and semiconductors using a plane-wave basis set," Computational Materials Science, vol. 6, no. 1, pp. 15-50, 1996.

[21] J. P. Perdew, K. Burke, and M. Ernzerhof, "Generalized gradient approximation made simple," Physical Review Letters, vol. 78, no. 7, article no 1396, 1997.

[22] N. A. Dubrovinskaia, L. S. Dubrovinsky, S. K. Saxena, and B. Sundman, "Thermal expansion of chromium (Cr) to melting temperature," Calphad, vol. 21, no. 4, pp. 497-508, 1997.

[23] P. A. Korzhavyi, A. V. Ruban, J. Odqvist, J.-O. Nilsson, and B. Johansson, "Electronic structure and effective chemical and magnetic exchange interactions in bcc Fe-Cr alloys," Physical Review B: Condensed Matter and Materials Physics, vol. 79, no. 5, Article ID 054202, 2009.

[24] B. Lee, M. Baskes, H. Kim, and Y. Koo Cho, "Second nearestneighbor modified embedded atom method potentials for bcc transition metals," Physical Review B: Condensed Matter and Materials Physics, vol. 64, no. 18, Article ID 184102, 2001.

[25] S. Plimpton, "Fast parallel algorithms for short-range molecular dynamics," Journal of Computational Physics, vol. 117, no. 1, pp. 1-19, 1995.

[26] S. Plimpton, "Fast parallel algorithms for short-range molecular dynamics," Journal of Computational Physics, vol. 117, no. 1, pp. 1-19, 1995, http://lammps.sandia.gov.

[27] H. J. Monkhorst and J. D. Pack, "Special points for Brillouinzone integrations," Physical Review B: Condensed Matter and Materials Physics, vol. 13, no. 12, pp. 5188-5192, 1976.
[28] S. R. Bahn and K. W. Jacobsen, "An object-oriented scripting interface to a legacy electronic structure code," Computing in Science \& Engineering, vol. 4, no. 3, pp. 56-66, 2002.

[29] Y. Mishin, M. Asta, and J. Li, "Atomistic modeling of interfaces and their impact on microstructure and properties," Acta Materialia, vol. 58, no. 4, pp. 1117-1151, 2010.

[30] I. M. Razumovskii, A. V. Ruban, V. I. Razumovskiy et al., "New generation of Ni-based superalloys designed on the basis of first-principles calculations," Materials Science and Engineering: A Structural Materials: Properties, Microstructure and Processing, vol. 497, no. 1-2, pp. 18-24, 2008.

[31] T. Ossowski, E. Wachowicz, and A. Kiejna, "Effect of iron additions on intergranular cohesion in chromium," Journal of Physics: Condensed Matter, vol. 21, no. 48, Article ID 485002, 2009.

[32] J. C. Slater, "Atomic radii in crystals," The Journal of Chemical Physics, vol. 41, no. 10, pp. 3199-3204, 1964.

[33] D. Scheiber, R. Pippan, P. Puschnig, A. Ruban, and L. Romaner, "Ab-initio search for cohesion-enhancing solute elements at grain boundaries in molybdenum and tungsten," International Journal of Refractory Metals and Hard Materials, vol. 60, pp. 7581, 2016.

[34] H. Jin, I. Elfimov, and M. Militzer, "Study of the interaction of solutes with $\Sigma 5$ (013) tilt grain boundaries in iron using densityfunctional theory," Journal of Applied Physics, vol. 115, no. 9, Article ID 093506, pp. 1-8, 2014.

[35] L. Vitos, A. V. Ruban, H. L. Skriver, and J. Kollár, “The surface energy of metals," Surface Science, vol. 411, no. 1-2, pp. 186-202, 1998.

[36] T. Ossowski and A. Kiejna, "Density functional study of surface properties of chromium," Surface Science, vol. 602, no. 2, pp. 517-524, 2008.

[37] F. R. De Boer, Cohesion in Metals, North-Holland, Amsterdam, 1988.

[38] W. Tyson and W. Miller, "Surface free energies of solid metals: Estimation from liquid surface tension measurements," Surface Science, vol. 62, no. 1, pp. 267-276, 1977.

[39] W. T. Geng, A. J. Freeman, and G. B. Olson, "Influence of alloying additions on grain boundary cohesion of transition metals: First-principles determination and its phenomenological extension," Physical Review B: Condensed Matter and Materials Physics, vol. 63, no. 16, 2001.

[40] V. N. Butrim, I. M. Razumovskiy, V. N. Kashirtsev, and A. G. Beresnev, "Chromating Alloy and Method of Alloy Melting," Patent RU2620405-C1, 2016. 

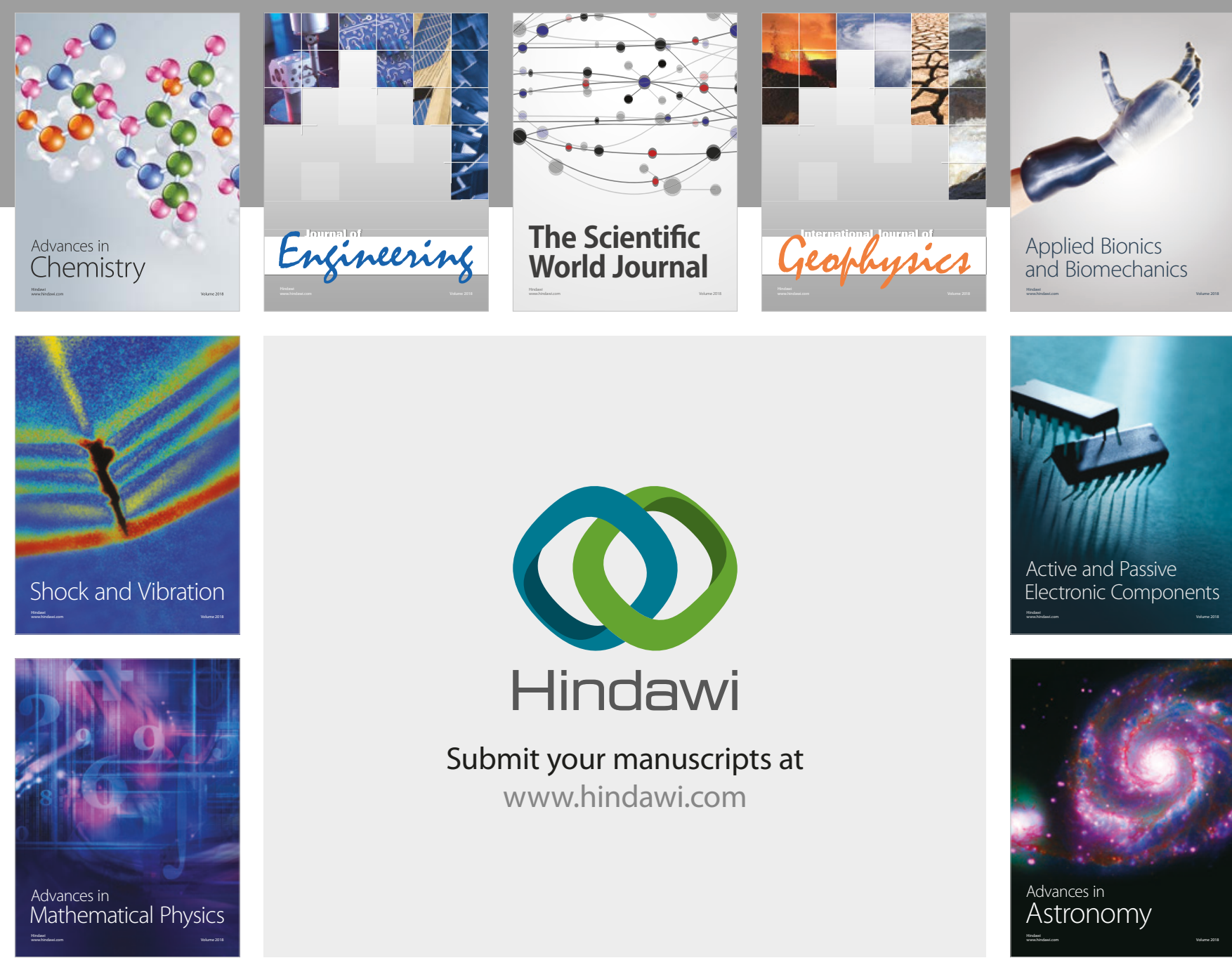

Submit your manuscripts at

www.hindawi.com

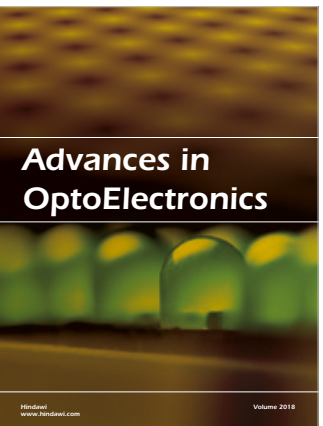

\section{Rotcting Machinery}
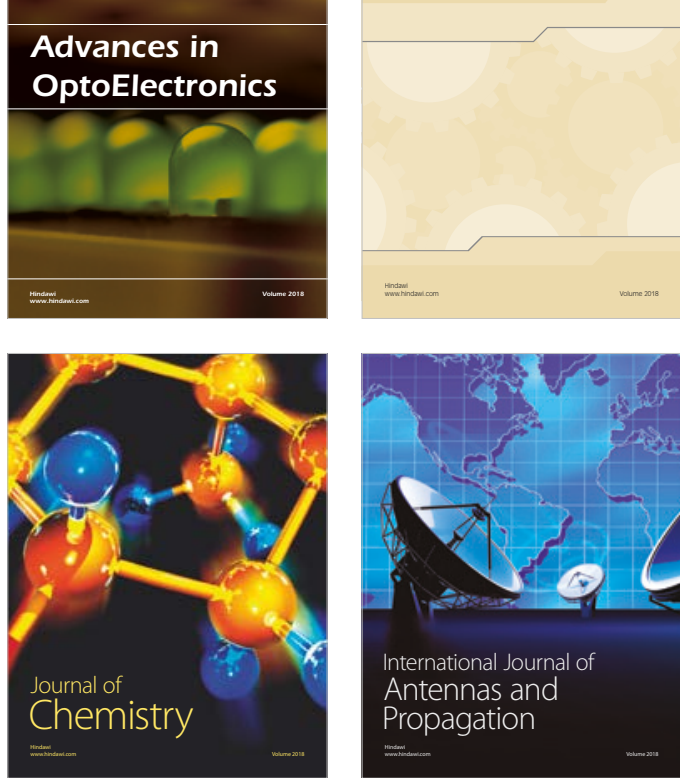

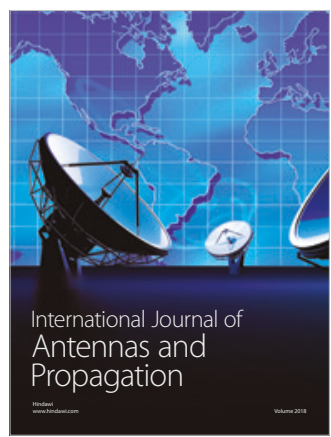

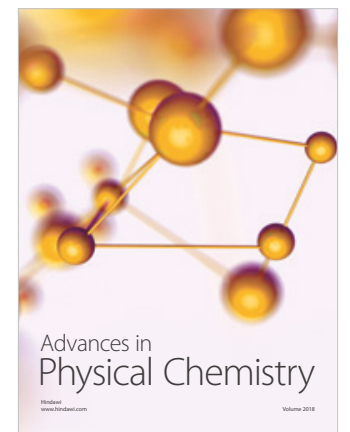

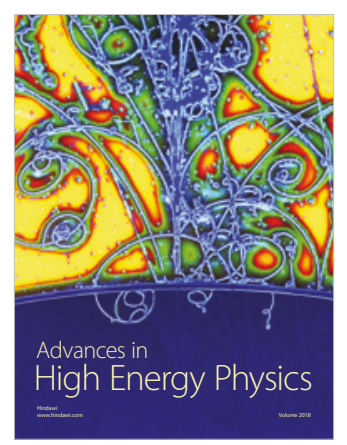

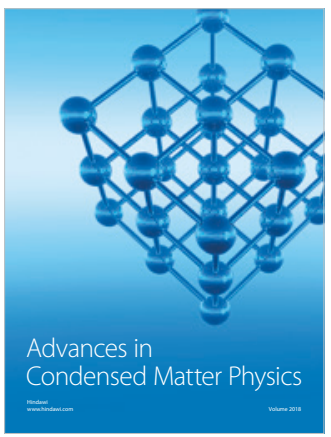

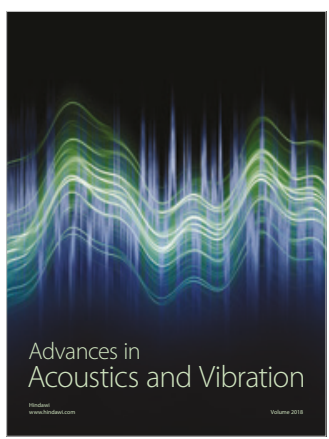

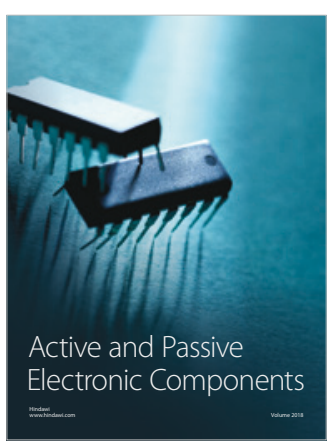
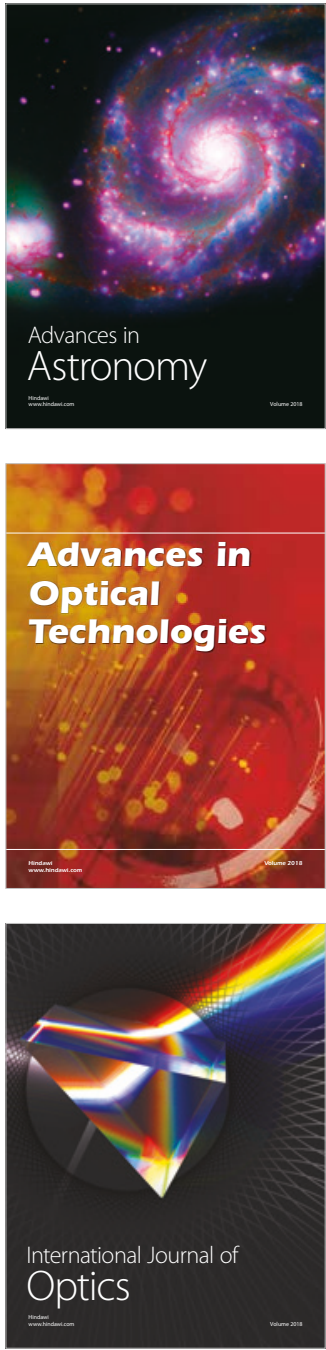